Revista Iberoamericana. $\quad$ Vol. LXII, Núm. 175, Abril-Junio 1996; 427-438

\title{
LA LITERATURA ARGENTINA DESDE 1980: NUEVOS PROYECTOS NARRATIVOS DESPUÉS DE LA DESAPARICIÓN DE CORTÁZAR, BORGES Y PUIG
}

\author{
POR \\ José AmícolA \\ Universidad Nacional de La Plata
}

BORGES Y SU PRESENCIA INSOSLAYABLE. LA TRADICIÓN COMO IMPOSICIÓN Y COMO CREACIÓN

Para abordar la literatura argentina actual parece inevitable hacer un poco de historia reciente y recordar las coordenadas de un campo literario con fuertes marcas autoriales. La labor de los escritores más jóvenes va a ser en el caso de la Argentina particularmente llamativa como conflicto frente a los padres y a su desaparición reciente. En efecto, en pocos años la muerte se llevó a tres autores que se hallaban en distinto grado de creatividad y que ejercían también distinto grado de atracción en la escritura argentina, pero cuya mención era inevitable. Cortázar murió en 1984, casi junto con el agotamiento de un proyecto que tenía a Sartre y a los surrealistas politizados como a sus mentores más evidentes. Borges, por su parte, se hallaba más allá de la adscripción epocal, habiendo recorrido en su discurso un camino obsesivo de temas y modos particulares que parecían girar intencionalmente en círculo. Su muerte, sin embargo, en 1986, no iba a significar más que la entrada en un territorio quasi mítico de la fama internacional de la mano de los teóricos más influyentes de Occidente. Por último, Puig murió prematuramente, en 1990, cuando su obra parecía todavía presagiar muchísimos cambios experimentales y cuando empezaba a ser conocida a nivel internacional. De la antigua generación quedan otros autores -como Sábato o Bioy Casares-que reciben hoy en día los galardones que le habrían correspondido a la literatura argentina en su conjunto. Esos supervivientes, sin embargo, no alcanzaron nunca el grado de influencia que lograron aquellos otros tres escritores argentinos muertos en los años antes mencionados. El caso de los escritores jóvenes argentinos de hoy es llamativamente el caso de una generación sin padres vivos, aunque no sin influencias.

La figura más fuerte de toda la literatura argentina moderna es, sin lugar a dudas, después del suicidio de Lugones en 1938, la de Jorge Luis Borges. Los autores jóvenes, por lo tanto, deben tomar partido en una apuesta a encolumnarse detrás de una "afiliación", según dice Said (1983). Esta presencia insoslayable de Borges, ya se daba mucho antes de que Borges trascendiera las fronteras argentinas, según lo pudo constatar un autor como Witold Gombrowicz, cuando él mismo pretendía ser un anti-Borges para lograr su propia personalidad artística. Como Gombrowicz, sin embargo, Borges había elegido el camino de oponerse a toda adscripción a una literatura regional. Para Borges y para Gombrowicz - autor polaco que pasó casi dos décadas en la Argentina como emigrado- la apuesta 
consistía en lograr universalidad. En el caso de Borges, el primer proyecto para ello consistía en recurrir a una tradición literaria que lo catapultara fuera del ámbito regional. Sin embargo, ni la tradición de la literatura gauchesca (como la frecuentó Ricardo Güiraldes) ni la de la literatura española (como la cultivó Enrique Larreta) representaban parámetros atractivos. Borges decidió, entonces, inventarse su propia tradición: por una parte, la de la cultura universal y, por otra parte, la de un mítico arrabal de Buenos Aires, que lo arrojaba al mundo que había conocido a través de las frecuentaciones paternas, con un código exótico de hombría y desafío que parecía absurdamente interpenetrado de color local, hasta llegar a ser una parodia del propio color local. La poética borgeana diseminada en sus escritos ensayísticos y semi-ensayísticos está transida por esa misma preocupación: cómo ser universal al mismo tiempo que profundamente argentino. Esta es la genial simbiosis que opera la maquinaria borgeana a través de espejos y laberintos, de paradojas y puestas en abismo.

En la elección borgeana hay, entonces, una negativa a aceptar la imposición que parece provenir de su condición de escritor argentino que trata de insertarse en un campo dominado por la figura del padre literario Leopoldo Lugones, quien había conseguido reubicar la tradición de la literatura gauchesca en una línea de abolengo. Este gesto de rebeldía habrá de consumarse en el universo de Borges primeramente a nivel de la búsqueda por la expresión, en la búsqueda de un "idioma de los argentinos", alejado del modernismo cuajado de destellos de la prosa y poesía lugonianas.

La sobriedad en el estilo de Borges y Bioy Casares. La renovación recatada de Cortázar. Las figuras de Arlt y Marechal entre los nuevos padres literarios.

La marca más llamativa en la nueva presencia que representa Borges es la imposición de un tono de voz que suene convincente como argentina, es decir de Buenos Aires, sin aparecer crispada por la imitación de lo español ni por la afectación de los modelos literarios. Borges, con la ayuda de otro joven de la gran burguesía, Adolfo Bioy Casares, proyecta con éxito la constitución de una nueva sensibilidad idiomática que debía recoger el nivel común de la oralidad, con un touch de gran refinamiento, una especie de "diccionario del argentino exquisito" (Bioy Casares 81-85). El primer ataque es disparado, entonces, contra el españolismo tomado de por sí como un valor de cambio. En este sentido, pues, debe entenderse la lucha de un sucesor, Julio Cortázar, cuando en su novela clave, Rayuela (1963), se burlaba a través de sus personajes de los diccionarios de la Real Academia Española.

La segunda enseñanza de Borges se hallaría en la dimensión temática. Como argentino, con gran cultura inglesa, Borges decide que su territorio de inspiración no podía ser solamente un acervo cultural como el argentino, privado de grandes culturas indígenas, sino aquél que conformaba el mosaico de todas las nacionalidades integradas al país a través de las olas inmigratorias. La Babel que representaba Buenos Aires en las primeras décadas del siglo permitía, al mismo tiempo, buscar cualquier veta con la seguridad de que habría representantes culturales en alguno de los anaqueles de las bibliotecas que se hallaban a su disposición. 
Cuando Cortázar se inicia en la literatura, lo hace con un cuento, "Casa tomada", que cuenta con el padrinazgo del propio Borges. A los dos los unía el común sentimiento de hostilidad hacia el primer peronismo y una adhesión contra la literatura llamada realista, incapaz para ambos de dar cuenta ya de la realidad. Cortázar, por su parte, va a crear relatos en los que la cotidianeidad del pequeño-burgués de la ciudad de Buenos Aires va a ser la piedra de toque para el salto mortal hacia una realidad de segundo grado, la realidad de los deseos o de los temores del inconsciente. Su norma literaria, con todo, va a seguir ateniéndose al idioma cuidado del hablante medio, forjado con un oído puesto en lo que su ámbito social consideraba no afectado. Al mismo tiempo que, a través de reflexiones metaliterarias va a atacar a los realistas del sistema literario y a los literatos de lenguaje pulido. La cruzada de Cortázar por el rehabilitamiento del pasado inmediato de la tradición literaria cuenta con dos éxitos notables que hay que mencionar aquí: la revalorización de Roberto Arlt, por una parte, y la de Leopoldo Marechal, por la otra. Cortázar pudo, en efecto, restituirlos al panteón literario argentino, con la aviesa intención de crearse para sí lectores que pudieran leerlo a él mismo, basándose en un substrato más amplio que aquél que le suministraba Borges. Ahora bien, el procedimiento de Cortázar al rehabilitar a esos dos escritores le permitió liberarse, en parte, de la influencia todopoderosa de su maestro y buscar otros padrinazgos. Si bien Cortázar no ejecuta el parricidio de Borges, aconsejado por Gombrowicz, por lo menos, agregando nuevos nombres a la constelación, hace menos obligatoria la relación de la influencia única. La mayor rebelión cortazariana se da justamente en la elección de un género literario que Borges no había frecuentado nunca, la novela; un género que, en cambio, Arlt y Marechal habían sabido crear para el público argentino en la nueva categoría de novela urbana. En efecto, Arlt con su ciclo novelístico de 1929/1931 Los siete locos/Los lanzallamas y Marechal con su novela paródica de 1948 titulada Adán Buenosayres, habían conmovido el sistema. Esto es lo que consigue también Cortázar cuando en 1963 funda la novelística anticanónica argentina con su Rayuela.

Arlt y Marechal, entonces, significan con su desaforado discurso narrativo una especie de antídoto contra la mesura de Borges y Bioy Casares. Estos dos últimos autores, sin embargo, siguen pesando en la concepción de Cortázar a nivel de las normas lingüísticas, mientras que los padres malditos de la literatura argentina le dan a Cortázar una nueva sensibilidad genérica.

El año 1968 y tres nOVElas Claves: NANINA, 62. Modelo PARA ARMAR Y LA TRAICIÓN DE RITA HAYWORTH.

El año 1968 aparece en múltiples sentidos como una divisoria de aguas en la Argentina, y no sólo en este país. Lo que había venido gestándose durante toda la década del 60 hace eclosión en ese momento para forzar a las sociedades a un cambio de paradigmas. En primera instancia, la liberación del ser humano encuentra su vocero en Marcuse, quien había bregado contra la unidimensionalidad del individuo. Mientras tanto, además, la politización creciente de las sociedades periféricas lleva a los escritores, y especialmente también a los escritores argentinos de ficción, a una toma de partido en las disputas sociales. La censura en los países dependientes con gobiernos mititares obliga, sin embargo, a una sutil perífrasis para expresarse. En Buenos Aires son pocas las casas editoriales que se atreven a arriesgarse 
contra el fantasma de la represión que castiga con cárcel y multas en dinero a los infractores. Una de estas pocas instituciones que aprovechan, sin embargo, los resquicios del poder autoritario se halla en la Editorial Jorge Álvarez, la que edita dos de las novelas más importantes del año 68: Nanina, de Germán García, y La traición de Rita Hayworth, de Manuel Puig. Por otro lado, la pujante Editorial Sudamericana, también de Buenos Aires, edita una obra de Cortázar titulada 62. Modelo para armar, cuyo título se construye sobre el capítulo 62 de su anterior novela Rayuela, y que, por lo tanto, parecería escrita para un público de iniciados. La novela de Cortázar del año 68 representa por la conformación de su trama una obra que sigue bajo el emblema de aquel Arlt rehabilitado, en el sentido de que los personajes que se mueven en ese universo discursivo no sólo continúan los de la novela anterior, sino que, al mismo tiempo, adopta las fórmulas tan bien utilizadas por Arlt de las conspiraciones (que terminan en el fracaso) y el contagio con las formas triviales, como la novela de horror. Por otra parte, 62. Modelo para armar, vuelve a apostar por la desarmonía constructiva en la que se promueve la iniciativa del lector.

En cuanto a la presencia de Marechal, ella resultaría especialmente llamativa en el juego paródico que había prodigado Adán Buenosayres para un grupo de intelectuales porteños. Lo que queda de borgeano en ella, sin embargo, es mucho: sobre todo, nuevamente, a nivel de la mesura en la elección del enfoque narrativo. En mi interpretación de esta novela, habría habido, entonces, en su autor una intención de equilibrar las dos influencias opuestas: Borges/Bioy, por un lado, y Arlt/Marechal, por el otro lado.

En cuanto a la obra de Germán García, Nanina, es interesante destacar que su novela fue leída en ese momento como una suerte de texto escandaloso o pornográfico, en medio del pudor que pretendía imporner el gobierno militar del General Onganía. En realidad, se trataba de un efecto de revitalización de la primera novela de Arlt titulada El juguete rabioso. En 1968 aparece también una novela en la misma editorial de un autor tan desconocido como Germán García, que, sin embargo, se queda sin lectores, dado que su proyecto es totalmente novedoso y no ha sido preparado desde ninguna de las plataformas anteriores. Se trata de La traición de Rita Hayworth, de Manuel Puig. La utilización de un acabado uso del monólogo interior a la manera de Faulkner desconcierta dentro de las técnicas conocidas por el público argentino y esa obra permanece prácticamente ignorada. Sólo será reeditada años después por la Editorial Sudamericana, cuando Puig haya conseguido imponerse con su segunda novela (del año siguiente), Boquitas pintadas. El proyecto de Puig es, sin embargo, uno de los más fuertes dentro de esta perspectiva, dado que pretende desligarse del pasado $\mathrm{y}$, sobre todo, dejar ya definitivamente la mesura borgeana, algo que logra con mayor convicción que Germán García. Tal vez, habría que decir que el planteo de Puig en su deseo de independencia de la tradición es justamente exitoso en el desembarazamiento de Borges, pero no en el peso que sobre él ejercen los lectores potenciales de Arlt y Cortázar, con quienes, a mi juicio, establece una línea marginal de recepción de la literatura argentina, especialmente en el aspecto de un cuestionamiento de las fronteras de la literatura llamada alta con los aledaños de lo que podría considerarse literatura de masas. Los lectores que consigue Puig deben primero pasar por el shock de sobreponerse a la nota kitsch que ofrecen sus títulos. 
La politización de la literatura en la década del Setenta. El hito de 1980: Saer / Piglia / PuIG.

Sabido es que a partir de la Revolución Cubana y, luego, con la aventura del Che Guevara en Bolivia, Latinoamérica sufre un proceso crucial de entrada en la resistencia política frente a los países centrales. Lo cierto es, también, que la politización de las juventudes, que durante la década del sesenta se habían sentido atraídos por el fenómeno de los "hippies", se transforma en un fenómeno de alcance mundial. Se vuelve a creer en la gran Utopía que había iluminado a los soñadores durante la década del veinte gracias a la creación de la Unión Soviética: el socialismo sería algo que se conquistaba por la disciplina individual y la solidaridad internacional. La gran expectativa ante lo que se creía esperando a la vuelta de cada esquina tiene en la Argentina su manifestación literaria en un tipo de escritura documental de denuncia, cuyo representante más cabal es el escritor Rodolfo Walsh, poco después víctima del sistema inicuo del terrorismo de Estado.

Esta corriente de una escritura que encuentra su razón de ser en un pacto con el realismo es la característica más saliente de la década del setenta, la que logra impregnar con su sello hasta a escritores antirrealistas como el mismo Cortázar, que escribe en 1973 El libro de Manuel, como un collage fabricado con noticias que el autor se siente obligado a dar a conocer. En 1976 Manuel Puig aporta su interpretación de ese momento con la extraordinaria visión dialógica de su novela El beso de la mujer araña, la que, sin embargo, desde el título pretende ser otra cosa que una crónica documental.

Si tomamos nuevamente un año clave, esta vez el de 1980, veremos que en ese lapso se publican nuevamente tres novelas que caracterizan tres tendencias de la novelística de la época: Respiración artificial, de Ricardo Piglia; Nadie nada nunca, de Juan José Saer; y finalmente Maldición eterna a quien lea estas páginas, de Manuel Puig. Allí estarían dados tres proyectos narrativos ejemplares que habrían de ser típicos de la década. Por una parte, Ricardo Piglia sigue homenajeando a Arlt con su escritura, tanto como a Borges, mientras Juan José Saer se enrola decididamente en la línea, que ya había tomado desde sus comienzos de escritor, declarándose un borgeano convencido. El tercer autor que vuelve a quedar separado del resto por la originalidad de su proyocto es nuevamente Manuel Puig, quien desde el título de sus obras se niega a aceptar el marco borgeano, para preferir el kitsch de la literatura trivial (Amícola, 1994).

Aquí habría que aclarar que en los últimos años la presencia insoslayable de Borges se ha extendido de tal modo que ya se lo considera el repositorio máximo a la hora de buscar no sólo inspiración para la teoría literaria -desde los descubrimientos que de Borges hicieron tanto Foucault, Eco, Derrida, como Jauss- sino que, al mismo tiempo, sus escritos han pasado a ser la última palabra para la explicación del canon literario en la Argentina. Existe, entonces, ya una doxa borgeana que es conocida por los intelectuates. De este conocimiento de lo que podría llamarse ya una Teoría de la Literatura Borgeana fue testimonio una mesa redonda que tuvo lugar en Buenos Aires el 15 de noviembre de 1994, en la que estuvieron presentes dos de esos tres autores claves del año 1980, que seguirán siendo importantes en el momento actual, y que ese día dialogaron sobre su quehacer literario. Entre las primeras preguntas surgidas se halló justamente la frase ya tópica de Borges extraída de uno de sus ensayos titulado precisamente "El escritor argentino y la 
tradición". Ricardo Piglia expresó al respecto en esa mesa redonda que en el momento en que un autor empieza a moverse no sabe exactamente dónde y cómo se coloca en ese espacio literario. Según Piglia puede suceder que ese autor joven junte en su genealogía literaria a otros autores cuyas relaciones de parentesco entre sí no sean visibles para nadie más que para él. Ante la misma pregunta, Juan José Saer, por su parte, respondió que la idea de una tradición al que el autor nuevo se adscribe es cierta, pero no es un fenómeno estático. El autor joven al insertarse en una tradición determinada, al mismo tiempo la modificaría. Saer y Piglia, por lo tanto, según se deduce de su participación en la mesa redonda mencionada, están de acuerdo en señalar el papel activo que le cabe al escritor al hacerse cargo del pasado. En este sentido, podemos decir que la tradición literaria es una magnitud que cada escritor vive con diferente grado de fuerza. Lo importante aquí, sin embargo, es que ella está marcando una serie de registros que pesan no sólo sobre el escritor, sino también sobre el público que realizará la recepción de la obra respectiva. Esto se ve con singular claridad en otro de los puntos que me interesa tratar aquí: la participación femenina en la literatura argentina.

LA PRESENCIA DE LAS MUJERES ESCRITORAS. LA NUEVA VOZ DE LA PEQUEÑa-BURGUESÍA (GRISELDA Gambaro y Ana Basualdo). La propuesta conjunta de Graciela Montaldo y Claudia GILMAN EN LOS NOVENTA.

Lo que llama la atención en la situación actual de los ofrecimientos que se presentan en la narrativa argentina es la avasallante presencia de escritoras. En esta última década, entonces, no sólo se ha destrabado un prejuicio general contra las mujeres a nivel sexual, sino que el público repentinamente se interesa por todo lo expresado por mujeres. En ese círculo se han visto implicados, entonces, en primera instancia los editores que ahora aceptan los manuscritos firmados por mujeres, y las propias escritoras que recogen el desafío. Por lo general, la Argentina ha tenido una abundante presencia femenina en la crítica literaria y en la cátedra universitaria, desde las autorizadas voces de María Rosa Lida y Ana María Barrenechea, en las décadas del cincuenta y sesenta. Sin embargo, entre las narradoras la Argentina sólo pudo contar en esas mismas décadas con dos escritoras notables, que, no por azar, pertenecían a la gran burguesía: Silvina Ocampo (hermana de Victoria Ocampo) y Sara Gallardo. Lo que parece un fenómeno nuevo es, sin embargo, que las nuevas voces femeninas ya no provengan de la clase privilegiada de los terratenientes, sino de la pequeña-burguesía.

Éste es el caso de una escritora que se hizo conocer primeramente a través de sus obras teatrales, pero que últimamente se ha dedicado también a la narrativa. Me refiero aquí a la singular Griselda Gambaro, cuyo discurso ya no responde a los estereotipos de lo que se ha considerado tradicionalmente lo femenino y que expresa en sus novelas todo el conflicto del hombre moderno perdido en la inmensidad de los signos, como sucede en su novela de 1994, titulada Después del día de fiesta.

Otra autora que me interesa mencionar aquí y que, a mi juicio, se destaca por sobre la mayoría de sus colegas es Ana Basualdo, cuya opera prima originariamente de 1985, acaba de reeditarse en una segunda edición con gran éxito de crítica. Se trata de una colección de cuentos con el nostálgico nombre de Oldsmobile 62. En ellos impera una mirada 
retrospectiva que los marca con una señal común, ubicándolos en el pasado no demasiado lejano de la vida suburbana de Buenos Aires en siestas interminables abrasadas por un calor llamativamente simbólico de los deseos sexuales que surgen de modo sutil de las páginas del texto, como si se tratara de consustanciaciones con las maquinarias herrumbradas fuera de funcionamiento que deslumbran por lo que fueron. Así operan en la escritura de Ana Basualdo un viejo auto o un viejo barco, lugar del encuentro del pasado o de la sexualidad, como de ecuaciones que se hallaran en el mismo plano. Esto produce un clima textual que recuerda el de algunos cuentos tempranos de Cortázar como el titulado "Final del juego".

$\mathrm{Si}$ la grandeza de un escritor puede medirse por las influencias que su obra pone en movimiento, es evidente que la producción de Puig está llamada a ocupar un lugar destacado junto a la de otros grandes nombres como Arlt, Borges y Cortázar. Como ejemplo de esto, quiero referirme a la influencia de Puig detectable en una novela como Preciosas cautivas (1993), de Claudia Gilman y Graciela Montaldo, en la que convergen la parodia del genre (la novela femenina epistolar) con la preocupación por la adscripción de gender. Esta obra tiene, además, el interés de que su temática establece un encabalgamiento de la acción por sobre el Río de la Plata, acentuando así la vinculación del campo tanto uruguayo como argentino en tanto espacios casi desterritorializados que se hallarían detenidos en un tiempo previo a la modernización de los dos Estados. Esta artimaña narrativa les permitirá a sus autoras describir de modo indirecto no sólo la unidad cultural de las dos sociedades, sino, al mismo tiempo, también marcar la problemática que ha sido el eje de este trabajo: el estereotipo sexual en el que se basa la concepción de gender y el constructo estético de un genre automatizado (aquí caras opuestas de la misma moneda). Emilia y Dora encarnan en esa novela todas las situaciones a las que se nos había acostumbrado en las obras de Puig, especialmente en las reflexiones como las que podían tener las protagonistas de Cae la noche tropical, donde Nidia y Luci dialogaban sobre los roles impuestos por la sociedad. Ellas son todas - Nidia y Luci/Emilia y Dora- las "preciosas cautivas" de las que hablan los géneros: la novela que se presenta como la novela femenina de la mujer (arcaicamente) virtuosa, que ya es la irrisión de sus modelos como la novela epistolar que la sostiene. El título de esta novela pone en escena, ya desde el principio, una batalla de los sexos que se remonta a las burlas contra las mujeres cultas del siglo XVII. Esa rápida cabalgata intertextual que ya enuncia el título va a recoger de pasada otra tradición: la que enrolaba a la mujer, desde el siglo XVII, como escritora absoluta de cartas. La novela epistolar de ese siglo pretendía recogerse en el intimismo, para hacerlo, sin embargo, público. El vuelco que establecen Gilman y Montaldo al canon, es tomarlo por las astas, de modo de transformarlo en la realidad de dos autoras mujeres que ficcionalizan una actividad para volverla del revés, estableciendo una verdadera correspondencia. Y si los casos de autoría conjunta no son nuevos en la Argentina, sí es nuevo que con ello se pretenda hacer una obra no trivial a partir de los estereotipos triviales. No es ajeno a esto, a mi entender, el hecho de que la autoría recaiga ahora en dos mujeres. Ellas son las que parecen haber recogido el guante que lanzo Puig como reacción contra la elegancia escrituraria de esa entidad con marca de fábrica de Borges, Bioy y Compañía. Pienso especialmente en el "desborgismo" que cunde en Hispanoamérica en la voz de escritoras como Angeles Mastretta (Arráncame la vida) o Rosario Ferré (Maldito amor). En este sentido, habría que coincidir con el juicio de Josefina Ludmer (Mayer) acerca de que los campos literarios tradicionales se hallan cada 
vez más globalizados a través del circuito abierto por la industria cultural, lo que llevará, finalmente, a que Latinoamérica conforme realmente un solo bloque cultural.

La obra reciente de Saer y Piglia. La crónica de la historia en dos escritores maduros: Andrés Rivera y Rodolfo Fogwill. El caso singular de Héctor Bianciotti.

Juan José Saer es un narrador nacido en la Provincia de Santa Fe. Comenzó a publicar en la década del sesenta, pero muy pronto fijó su residencia en Francia, desde donde siguió escribiendo en su lengua materna con una temática abundantemente argentina. Su éxito (y difusión) como autor extremadamente refinado le llegó relativamente tarde, en la última década, aunque sus libros se siguieron editando siempre en su país de origen. El último de ellos utiliza la devoción borgeana por la trama policial, aunque modifique profundamente el género que parece invocar. Su título goza de toda la mesura de la que sería capaz un borgeano como Saer: La pesquisa (1994). Me permito recomendar aquí, sin embargo, su obra de ensayista con El río sin orillas, de 1991.

Ricardo Piglia, por su parte, es uno de los autores que se caracterizan por dedicar gran parte de su energía a la lectura y comentario a través de seminarios extra-académicos sobre la teoría literaria. Este hecho se refleja en su obra ficcional de tal modo, que muchas de sus narraciones parecen ejemplificar una determinada corriente metodológica en debate público. Su última novela se titula La ciudad ausente y data de 1992. En ese título también profundamente mesurado Piglia hace una alusión sutil a un sintagma que podría remitir a la idea central de The Empty Fortress (1967), de Bruno Bettelheim (1903-1190), quien utilizó esa metáfora para referirse a la enfermedad del autismo en niños. Aquí la fortaleza vacía sería una Buenos Aires fantasmal que mira sólo hacia dentro de sí a través de una máquina narrativa que es la propia novela que se desarrolla ante nuestra lectura, síntesis del pasado. Por otra parte, esta idea de la narración como máquina que cuenta parece remitir a ideas similares expresadas en el postestructuralismo francés, del que la Argentina es una reconocida caja de resonancia. La ciudad ausente puede entenderse también como un símbolo de la asfixia política de las últimas décadas y por ello remitir al título anterior del mismo Piglia, Respiración artificial, donde se daba ya la imagen de un cuerpo en situación de una enfermedad mortal. El éxito, por lo menos en los pequeños medios intelectuales, que coronó a la última novela de Piglia se evidencia en el hecho de que para el presente año se halla programada una versión operística para ser estrenada en el Teatro Colón de Buenos Aires, con música del compositor Gerardo Gandini.

Del mismo modo que Piglia y Saer — dos baluartes de la literatura argentina actual que normalmente se mencionan juntos - significan un proyecto sutil de recuperación del pasado histórico a través de técnicas literarias muy refinadas (la inclusión de la teoría literaria y la reflexión sobre la tradición de la literatura argentina anterior en Piglia o el mundo narrativo sutilmente borgeano permeado de una admiración cabal por la literatura francesa, en especial por Proust y el nouveau roman en el caso de Saer), la obra de otros dos escritores actuales, Andrés Rivera y Rodolfo Fogwill, podría mencionarse en una misma línea de afinidad electiva, en tanto ambos son conscientes de una labor quasi cronística del narrador de ficción. Una de las novelas más interesantes de Andrés Rivera, un autor que se lanzó a la escritura en la década del sesenta, se titula La revolución es un sueño eterno y ya 
en el año de su aparición, 1993, fue coronada con el Premio Nacional de Narrativa. Ella parecería ser por su temática una contestación al ideologema del fin de los grandes relatos y del fin de la historia. La apuesta de Rivera va a contrapelo de estas aseveraciones, al tomar como base de su novela histórica a Juan José Castelli, un personaje lateral de la época de liberación del Río de la Plata de la monarquía española. La sutileza de esta visión sesgada de la historia nacional no le va en zaga a las empresas también muy sutiles de Saer o Piglia, con quienes comparte la devoción por cierta morosidad narrativa. En efecto, el personaje Castelli escribe (en primera persona) su diario íntimo y, al hacerlo, construye así una novela que está tomando al personaje real como trampolín para retratar un proceso revolucionario, que, en definitiva, podría ser cualquiera de los tantos que se han visto desde 1789 a través de personajes marginados por la ola revolucionaria: el de Babenf en Francia o el de Trotski en la Unión Soviética.

El caso de Rodolfo Fogwill es igualmente interesante y quizás más urticante todavía, porque en su novela Los Pichy-cyegos se trata de hacer una crónica antioficial de un hecho histórico reciente: la guerra de Malvinas (o Falklands) que ocurrió en 1982. El libro fue publicado originariamente en 1983, pero sólo en su nueva edición de 1994, consiguió atraer la atención de la crítica, y por eso es comentado aquí como entre otras obras recientes. La astucia narrativa de la novela consiste, como en el caso de la de Rivera, de dotar a la historia de una mirada que proviene no desde una presunta objetividad histórica, sino de la inmersión directa junto a los personajes que podían haber sido sus protagonistas. "Pichycyegos" son en la novela un grupo de soldados argentinos que se construyen entre las rocas de las islas Malvinas una gruta para sobrevivir al frío y al hambre que los diezma. En esta empresa bestial se revelan algunas de las fallas fundamentales de esa guerra, así como se pone en entredicho el mentado patriotismo de los participantes. La herejía histórica consiste, además, en inventar en la trama un pacto de entendimiento con un grupo de ingleses enemigos para poder sobrevivir a las condiciones casi polares del lugar. El emblema de este pacto está dado no sólo por el trueque de información (que significaría una traición a la Patria), sino por el más estrecho del contacto sexual entre soldados de bandos opuestos. El más reciente espaldarazo a esta novela ha venido de alguien tan prestigiosa como Beatriz Sarlo, quien en la revista de la que es directora desde su fundación en 1978, Punto de Vista, ha proclamado la excelencia de una novela que se ha atrevido, por primera vez, a burlarse del tan remanido patriotismo argentino (Sarlo).

Un caso especial representa para la consideración del campo literario argentino la narrativa de Héctor Bianciotti, autor nacido en la Provincia de Córdoba, de padres inmigrantes, como Juan José Saer, y que también ha elegido como tierra de adopción Francia. La diferencia con Saer, radica para Bianciotti en que a partir de la década del ochenta ha abandonado no sólo la frecuentación de su campo literario inicial, sino, al mismo tiempo, su lengua materna. Este caso produce un quiebre en la consideración general de mi exposición, en tanto el autor considerado ni su obra figuran en el debate literario argentino. Con todo, me interesa traer a colación que su novela de 1992, Ce que la nuit raconte au jour (cuyo título en castellano sería: Lo que la noche cuenta al día), es una autobiografia que ubica la acción en el campo argentino de la infancia del escritor a la manera de la de William Henry Hudson. 
Los escritores jóvenes: César Aira, Marcelo Cohen, Daniel Guebel y Sergio Chejfec.

Entre los escritores que se hallan entre los 38 y 45 años de edad hay un grupo tan impresionante de autores ya publicados por las nuevas editoriales españolas instaladas ahora en Latinoamérica como Alfaguara, Alianza, Tusquets, Planeta y Seix Barral que resulta muy difícil hacer un pronóstico claro sobre quiénes podrán dominar la escena literaria en los próximos años. Lo cierto es que autores consagrados como Saer, a la hora de hacer ese pronóstico recuerdan los nombres de Cohen, Pauls, Cheifec, dal Masetto y Martini. Beatriz Sarlo desde sus clases de la Universidad de Buenos Aires y desde la revista Punto de Vista, insiste, por su parte, en la importancia de Marcelo Cohen, Sergio Cheifec y Héctor Tizón (este último de una generación anterior). Por otro lado, la prensa repite también otros nombres nuevos como los de Álvaro Abós y Carlos Feiling, que se han sumado al nutrido campo literario en los últimos cuatro años. Lo llamativo en estas listas es que no aparezcan recomendadas mujeres de las muchas que han accedido a la escritura. Por mi parte, me inclino por dar aquí una idea general, sin embargo, de las obras que, en mi opinión, registran un mayor caudal de proyectos narrativos de renovación. Ellas serán las de César Aira, Marcelo Cohen, Sergio Chejfec y Daniel Guebel.

César Aira (1949-) es uno de los escritores más prolíficos de la nueva literatura argentina. Su escritura acusa recibo de la influencia de Puig, por un lado, en cuanto a la ambigüedad que rodea a las caracterizaciones de gender y, por otro, entra de lleno en un deseo, que lo ubicará con sus pares generacionales, de evitar la referencialidad que fue la característica del proyecto discursivo de la década del setenta. Sus narraciones juegan, entonces, con una concepción muy particular de lo verosímil, que ya no cubre ni siquiera el dicho borgeano sobre la huida del color local que ha pasado a ser una receta en el canon literario argentino con aquello de que "en el Corán no hay camellos". Aira y sus coetáneos crean una realidad tan novedosa que termina por ser fantástica a fuerza de marcas de la realidad. Su relectura paródica de la tradición literaria, por otra parte, recuerda los procedimientos borgeanos de distanciamiento irónico sobre el pasado. Así por ejemplo en La liebre (1991), su novela más ambiciosa.

Marcelo Cohen (1951-) es, desde su puesto de trabajo en Barcelona, uno de los que reconstruyen ámbitos reconocibles como argentinos a fuerza de un borramiento de marcas, como en el cuento de Borges "El jardín de los senderos que se bifurcan". En su colección de cuentos titulados El fin de lo mismo (1992), los shopping centers se han transformado en catedrales de la postmodernidad, donde los personajes deambulan con un secreto inquietante, como es el hecho de poseer un tercer brazo que debe ser disimulado debajo de la chaqueta. En ello se respira un malestar en la cultura, cuya referencialidad alcanza la misma sutileza de universalismo que obtenían los primeros cuentos de Cortázar.

El mundo imaginario de Daniel Guebel (1956-) recrea, al modo de Salgari, las novelas de aventuras donde lo que cuenta es el placer de la fabulación. Esto sucede en La perla del emperador (1990), cuya elegancia en la construcción de una trama radica en que ella termina por morderse la cola para no llegar a ninguna parte. Lo borgeano sería justamente aquí el gusto por la construcción de la trama perfecta, que, sin embargo, aparece en estado de parodia. 
Sergio Chejfec (1956-) publicó su novela El aire también en 1992 y ella le dio un lugar en el espacio literario argentino gracias a su dominio de los matices que juegan con la psicología de un personaje inmerso en una ciudad donde la moneda de cambio es ahora el vidrio de las botellas vacías, lo que llega a un nivel de pesadilla, comparable al clima creado por Cortázar en una novela como El examen. En un artículo teórico el mismo autor dijo: "Aludiendo, en su desarrollo entrópico, a múltiples sentidos, la novela no representa la realidad, no refiere la verdad, no garantiza que sus mismas palabras tengan una razón precisa o unívoca para estar donde están. Estas negatividades buscan recuperar un enigma olvidado en la mente de escritores y lectores, el misterio que se interroga sobre el sentido último de las cosas: ‘¿Qué estamos haciendo acá, en la tierra, después de todo?' Y cuando consigue inducir la pregunta es una narración lograda" (Chejfec, 1994, 34). Estos serían, entonces, los lineamientos típicamente antirreferenciales de los proyectos de las últimas generaciones.

\section{CORPUS BÁSICO PARA ESTA EXPOSICIÓN}

(LIBROS EDITADOS DESDE 1990)

Abós, Alvaro. El simulacro. Buenos Aires: Sudamericana, 1994.

Aira, César. Los fantasmas. Buenos Aires: GEL [Grupo Editor Latinoamericano], 1990. La liebre. Buenos Aires: Emecé, 1991. El bautismo. Buenos Aires: GPI, 1991. La prueba. Buenos Aires: GEL, 1992. Cómo me hice monja. Rosario: Beatriz Viterbo Editora, 1993. Los misterios de Rosario. Buenos Aires: Emecé, 1994.

Basualdo, Ana. Oldsmobile 1962 (1985). Buenos Aires: Alfaguara, 1994.

Bianciotti, Héctor. Ce que la nuit raconte au jour. París: Grasset, 1992.

Bioy Casares, Adolfo. Memorias. Buenos Aires: Tusquets, 1994.

Bizzio/Guebel. Dos obras ordinarias ("La China"/"E1 amor"). Rosario: Beatriz Viterbo Editora, 1994.

Cheifec, Sergio. El aire. Buenos Aires: Alfaguara, 1992.

Cohen, Marcelo. El fin de lo mismo. Buenos Aires: Alianza, 1992.

Feiling, Carlos E. Un poeta nacional. Buenos Aires: Sudamericana, 1993.

Gambaro, Griselda. Después del día de fiesta. Buenos Aires: Seix Barral, 1994.

Gilman/Montaldo. Preciosas cautivas. Buenos Aires: Alfaguara, 1993.

Guebel, Daniel. La perla del emperador. Buenos Aires: Emecé, 1990.

Fogwill, Fodolfo E. Los Pichy-cyegos. Buenos Aires: de la Flor, 1983.

dal Masetto, Antonio. La sierra incomparable. Buenos Aires, Planeta, 1994.

Martini, Juan. El fantasma imperfecto (1986). Buenos Aires, Alfaguara, 1994.

Pauls, Alan. Wasabi. Buenos Aires: Alfaguara, 1994.

Piglia, Ricardo. La ciudad ausente. Buenos Aires: Sudamericana, 1992.

Rivera, Andrés. La revolución es un sueño eterno. Buenos Aires: Alfaguara, 1993. El verdugo en el umbral. Buenos Aires: Alfaguara, 1994.

Saer, Juan José. El río sin orillas. Tratado imaginario. Buenos Aires: Alianza, 1991. La pesquisa. Buenos Aires: Seix Barral 1994.

Tizón, Héctor. El gallo blanco. Buenos Aires: Alfaguara, 1992. 


\section{BIBLIOGRAFÍA TEÓRICA}

Amícola, José. Manuel Puig y la tela que atrapa al lector. Buenos Aires: GEL, 1992. "El escritor argentino y la tradición borgeana". Espacios de Crítica y Producción 15, Facultad de Filosofia y Letras de la Universidad de Buenos Aires, 1994.

Balderston, Daniel y otros. Ficción y política. La narrativa argentina durante el proceso militar. Buenos Aires: Alianza, 1987.

Chejfec, Sergio. "Entropia". Punto de Vista 48 (Buenos Aires, abril de 1994).

Giordano, Alberto. La experiencia narrativa. J.J. Saer-F. Hernández-M. Puig. Rosario: Beatriz Viterbo Editora, 1992.

Gramuglio, María Teresa. "La summa de Bourdieu". Punto de Vista 47 (Buenos Aires, diciembre de 1993).

Ludmer, Josefina (Comp.). Las culturas de fin de sigloen América Latina. Rosario: Beatriz Viterbo Editora, 1994.

Mayer, Marcos. "Fin de siglo latinoamericano", entrevista a J. Ludmer en diario Páginal 12 (Buenos Aires, 8 de enero de 1995).

Mercado, Tununa. La letra de lo minimo. Rosario: Beatriz Viterbo Editora, 1994.

Perilli, Carmen. Las ratas en la torre de Babel. La novela argentina entre 1982 y 1992. Buenos Aires: Letra Buena, 1994.

Piglia, Ricardo. Crítica y ficción. Buenos Aires: SigloVeinte, 1990.

Rama, Ángel (Comp.). Más allá del boom: Literatura y mercado. Buenos Aires: Folios Ediciones, 1981.

Russo, Miguel. "Ficciones en la historia", en diario Página/12 (Buenos Aires, 18 de diciembre de 1994).

Saavedra, Guillermo. La curiosidad impertinente. Entrevistas con narradores argentinos. Rosario: Beatriz Viterbo Ediciones, 1993.

Said, Edward W. The World, the Text and the Critic. Boston: Faber \& Faber, 1984.

Sarlo, Beatriz. "No olvidar la guerra de Malvinas. Sobre cine, literature e historia". Punto de Vista 49 (Buenos Aires, agosto de 1994).

Speranza, Graciela. "Josefina Ludmer. Nuevas miradas de la crítica". Entrevista en diario Clarin (Buenos Aires, 29 de diciembre de 1994).

Spiller, Roland (Comp.). La novela argentina de los años 80. Frankfurt: Vervuert, 1991. 